\title{
Research on the Integration Path of Technology Innovation and Business Model Innovation in Special-Purpose Vehicle Enterprises
}

\author{
XIAO ming ${ }^{1}$ \\ School of Management, Wuhan University of Technology \\ Wuhan 430070, China
}

\author{
LIU yi-xuan ${ }^{2}$ \\ School of Management, Wuhan University of Technology, \\ Wuhan 430070, China
}

\begin{abstract}
The integration of technological innovation and business model innovation has become an important part of Chinese "Innovation-driven Development Strategy" at this stage. Based on the analysis on relevant literatures and personal interviews, this paper proposed the integration path of the two types of innovation, in order to solve the problems faced by special-purpose vehicle enterprises under the new market conditions. Based on the conceptual model of the integration path, this paper provided the following suggestions for the development of special-purpose vehicle enterprises: focus on customer value, be guided by market demand, refine corporate governance, reduce technical barriers, reshape marketing strategies, and strengthen the level of technological innovation and the capability of industrial transformation of new products so as to create new profit driving force and improve corporate profitability. This research will theoretically enrich the research of the integration path of technological innovation and business model innovation, and provide theoretical guidance for special-purpose vehicle enterprises to obtain long-term market competitiveness in practice.
\end{abstract}

Keywords-Special-vehicle market; Technological innovation; Business model innovation; Integration path

\section{INTRODUCTION}

In the report of the 19th National Congress of the Communist Party of China held in October 2017, more than 50 times mentioned innovation, further clarifying the important position of innovation in leading economic and social development. General Secretary Xi Jinping once again emphasized theoretical innovation and practice. Innovation, institutional innovation, cultural innovation and other aspects of innovation, China is accelerating the construction of innovative countries. Earlier, the party's 18th National Congress proposed to implement an innovation-driven development strategy, with particular emphasis on strengthening technology integration and business model innovation.

In addition, the "Opinions of the Central Committee of the Communist Party of China and the State Council on Deepening the Reform of System and Mechanism to Accelerate the Implementation of Innovation-Driven Development Strategy" pointed out that including the overall thinking and main objectives, creating a level playing field for incentives and innovation, and establishing a market-oriented mechanism for technological innovation, Strengthen the function of financial innovation, improve the incentives for transformation of results, build a more efficient scientific research system, innovate, cultivate and use talents, promote the formation of deep integration and open innovation, and strengthen the coordination and coordination of innovation policies. The "Opinions" require creating a level playing field that encourages innovation. Give play to the fundamental role of market competition and encourage innovation, create a fair, open and transparent market environment, strengthen the guidance of innovation by competition policy and industrial policy, promote the survival of the fittest, and enhance the innovation power of market players. Implement a strict intellectual property protection system, break the industry monopoly and market segmentation that restrict innovation, improve the access management of new technologies, new products and new business models, improve industrial technology policies and management systems, and form innovative mechanisms for factor prices. The integration and interaction of business model innovation and technological innovation has become an important part of China's implementation of innovation-driven development strategy at this stage.

As the main body of implementing the innovation-driven strategy, special-purpose vehicle enterprises directly participate in the national economic construction, and they are all contributing to the development of economic construction, whether for transportation or construction operations. With the sustained and steady development of the national economy, the increasing investment in fixed assets, and the improvement of the construction of logistics networks, the market for special-purpose vehicles in China has shown an upward trend as a whole. Despite the rapid development of the special-purpose vehicle industry, the special-purpose vehicle market is relatively large and complex. The existing problems cannot be underestimated, such as poor supervision, insufficient level of technological innovation, and insufficient innovation in business models. Most companies only pay attention to the increase in sales volume, but lack strategic ideas in improving their innovation capabilities, market and technology development. With the intensification of market competition and the increase of product cost, the competitive advantage of labor-intensive products to win by price will be further weakened. Enhancing the market competitiveness of special-purpose vehicle enterprises through technological innovation and business model integration and innovation to 
help promote the development of special-purpose vehicle enterprises.

How to realize the integration of technological innovation and business model innovation in special-purpose vehicle enterprises has become the focus of academic and industry attention. Based on the previous studies, this paper proposes a related fusion path for special-purpose vehicle enterprises, in order to provide theoretical support for the special vehicle enterprises to gain market competitiveness.

\section{LITERATURE REVIEW}

\section{A. Business model innovation related literature}

The current research on business model innovation by scholars at home and abroad mainly focuses on the definition and development process of business model concept, the connotation, influencing factors and innovation path of business model innovation.

\section{1) Definition of business model development process}

Business models appear as specialized terminology in the management literature in the mid-1970s. In the 1980s, the concept of business models began to appear in the literature reflecting the dynamics of the IT industry. In the mid-1990s, the business model became popular as a buzzword in the corporate world and gradually attracted the attention of the theoretical community. The emergence of entrepreneurial society in the early 21 st century made the business model attract the attention of mainstream society [1].

\section{2) The connotation of business model innovation}

The relevant theoretical system of business model is relatively mature, scholars pointed out that the so-called business model innovation refers to the change or improvement of the business model as a whole. It can be triggered by the change of one or several key elements, but the final result must be the impact on all aspects of the business model. And make the business model change as a whole. At the same time, business model innovation has obvious characteristics of holistic, extroverted and effective [2].

\section{3) Influencing factors of business model innovation}

The factors influencing the innovation of business model can be classified into the influencing factors of business model innovation from the perspectives of technology promotion, demand promotion, competition pressure and enterprise innovation spirit [3]. Business model innovation is a process of internal and external repair. Eight factors can be the leading cause of business model innovation: management cognition, resource capacity, organizational activities and profit model; technological innovation, situational factors, market opportunities and value networks Innovation in the business model of the enterprise. And the antecedents of incumbent companies and start-ups in business model innovation are different [4].

\section{4) Business model innovation path}

The research on the path mainly focuses on the following three categories: one is the innovation path based on the component elements, also called the static innovation path; the second is the process-based innovation path, the literature mainly examines both the stage and the dynamic; the third is based on The innovative path of price and value chain perspective [5].

\section{B. Relevant literature on technological innovation}

Scholars' research on technological innovation mainly focuses on the development of technological innovation theory and the evaluation of innovation ability.

1) Development history of technological innovation theory

For the evolution of the theory of technological innovation. At present, the research and development of foreign technological innovation theory has formed four major theoretical schools, including the neoclassical school, the new Schumpeterian school, the institutional innovation school and the national innovation system school. Judging from the scope of current domestic theoretical research on technological innovation, China's technological innovation research basically has three perspectives, namely, economics, management and technical philosophy or technical sociology, economic research and management of technological innovation. Research constitutes the mainstream of domestic theoretical research on technological innovation [6]. Domestic scholars pay attention to two types of technological innovation models: independent innovation and cooperative innovation. Foreign scholars' research on technological innovation models focuses on the internal perspective of enterprises and the external perspective of enterprises [7].There are differences in the entry points for theoretical research on technological innovation at home and abroad, which means that research may be carried out from different angles and there will be differences.

2) Evaluation index of technological innovation capability Aiming at the defects and shortcomings in the current enterprise technology innovation performance evaluation system, scholars combined with the characteristics of technological innovation and the innovation reality of Chinese enterprises, designed a new type of enterprise technology innovation performance evaluation index system [8]. In addition, the technological innovation capabilities of different types of enterprises are constructed from other perspectives. There are still a lot of evaluation indicators, so here is not an example.

\section{Relevant literature on the relationship between technological innovation and business model innovation}

At present, more people accept the view that technological innovation and business model innovation are mutually causal, technological innovation promotes business model innovation, and business model innovation is inseparable from technological innovation. There are also related researches on the path of coordinated development of enterprise technology innovation and business model innovation under the "Internet + " strategy. At the same time, the presentation of the model of the second business model innovation and technological innovation further promotes the integration of the two type of innovation [9]. However, some scholars have pointed out that the business model is crucial for new and existing enterprises in developed and emerging economies, but its relationship with strategy and how it helps companies to obtain value from technological innovation remains to be explored [10]. It can be seen that the academic community has not yet reached a 
consensus on the relationship between the two types of innovation. Most scholars believe that business model innovation and technological innovation are complementary. The interaction between the two has a positive impact on corporate performance, but some scholars believe that the relationship between the two needs to be explored. .

In summary, domestic and foreign scholars have more research theories related to technological innovation and business model innovation, and the system is relatively mature, including the definition and development process of business model concepts, the connotation, influencing factors and innovation paths and technologies of business model innovation. Innovation theory development and innovation ability evaluation. However, most of the two types of innovation are studied separately, and the research results under the unified research theory framework are few. At the same time, domestic and foreign scholars have not yet reached an agreement on the relationship between the two and the coupling mechanism. On the basis of previous studies, the fusion path of technological innovation and business model innovation based on the special vehicle market needs further exploration.

\section{Specialized Vehicle Market TeChNOLOGY INNOVATION AND BUSSINESS MODEL INNOVATION INTEGRATION}

I take the special-purpose vehicle enterprise as an example. The technological innovation will bring about the improvement of the productivity and process level of auto parts and the increase of product diversity. Through continuous technological innovation, it will help enterprises get rid of the dilemma of product simplification, and the company is increasingly in the special-purpose vehicle industry. Winning a broader sales market in a fiercely competitive environment. The industrialization and commercialization of new products improved through technological innovation will promote the growth of corporate profits and promote the innovation of profit models. In the new market environment, the main body of each enterprise will reposition its value proposition in order to increase market opportunities. At the same time, the improvement of the technical environment will stimulate the market demand for new products and drive consumption. At this time, the original enterprise management system, such as forecasting and evaluation capabilities, internal and external coordination capabilities, etc., are no longer suitable for the new environment and will promote the new one. Round innovation integration.

With the strengthening of competition, the concept of customer value as the core has been deeply rooted in the hearts of the people. This puts higher requirements on the special-purpose vehicle enterprises: First, make a correct judgment on the development trend of customer value orientation, and make correct decisions on the future market competition trend. Phased forecasting. Second, according to the characteristics of their own resources, strategic choices. Special-purpose car companies need to put the customer value proposition at the core position, and strive to understand the needs of each customer. The company must grasp the most important elements of the target customers and demonstrate the advantages of their new products and new technologies, so as to cultivate customers' products. Preference and loyalty. Due to the large number of special-purpose vehicle companies and their inconsistencies, the technical content is low. Special-purpose vehicle industry has fierce competition and repeated service provision. Special-purpose vehicle enterprises should improve their technical barriers, establish a mature marketing system, improve management level, improve marketing policies, and improve user satisfaction, so as to gain competitiveness in the industry.

In addition to adjusting the industrial structure, we should also actively improve product quality, transform to intelligent manufacturing, and respond to the "China's smart creation" national development strategy. For the special-purpose vehicle enterprises, the customer-centered, market-oriented, and around the manufacturing services industry, in the high-end special vehicles, capital operations, automotive recycling and remanufacturing, automotive core parts and other aspects of mining new profit growth points It will become the main development direction of its innovation and development.

\section{CONCLUSION}

Take the special-purpose vehicle enterprise as an example, the value proposition and the innovation of the value chain will become essential elements for the integration of technological innovation and business model innovation. Technological innovation will bring about an increase in the productivity and technological level of auto parts, and an increase in product diversity. Through continuous technological innovation, it will help enterprises get rid of the dilemma of product simplification, and win more for the enterprises in the increasingly competitive environment of the special-purpose vehicle industry broad sales market.

The industrialization and commercialization of new products improved through technological innovation will promote the growth of corporate profits and promote the innovation of profit models. In the new market environment, the main body of each enterprise will reposition its value proposition in order to increase market opportunities. At the same time, the improvement of the technical environment will stimulate the market demand for new products and drive consumption. At this time, the original enterprise management system, such as forecasting and evaluation capabilities, internal and external coordination capabilities, etc., are no longer suitable for the new environment and will promote the new one. Round innovation integration.

Due to the complexity of the external environment of the market and the complexity of the internal structure of the enterprise, the future can be explored from a broader perspective, such as considering the impact of technological innovation and the degree of integration of business models on corporate performance, so as to study more deeply. The integration of technological innovation and business model innovation. Therefore, the research on the factors and angles that affect the integration of technological innovation and business model innovation in special-purpose vehicle enterprises needs to be expanded. The path of integration of the two types of innovation needs to be further explored. 


\section{ACKNOWLEDGMENT}

This research was funded by the 2018 National College Students Innovation and Entrepreneurship Training Program (No.201810497280).

\section{REFERENCES}

[1] Guo Yifu, Zhao Xiaokang. Research and development prospects of business model innovation [J]. Enterprise Vitality, 2009 (03): 94-96. (In Chinese)

[2] Qi Yan. Research on business model innovation [D]. Beijing University of Posts and Telecommunications, 2010. (In Chinese)

[3] Chen Chen. A review of the influencing factors of enterprise business model innovation under the "+" era of the Internet[J]. Modern Business, 2016(25): 127-129. (In Chinese)

[4] Wu Xiaobo, Zhao Ziyi. Antecedents of Business Model Innovation: Research Summary and Prospects [J]. Foreign Economics and Management, 2017, 39(01): 114-127. (In Chinese)

[5] Tian Qingfeng, Zhang Yinyin, Yang Qing. Business model innovation: a review of theoretical research progress and empirical research [J]. Management Modernization, 2018, 38 (01): 123-128. (In Chinese)

[6] Peng Jingli, Deng Yi, Li Jianping. The Progress and Development Trend of Theoretical Research on Technological Innovation at Home and Abroad [J]. Technology and Economy, 2006 (04): 13-16. (In Chinese)

[7] Feng Chaojun, Mi Mi, Wen Wei. A Summary of Research on Technology Innovation of Small and Medium Enterprises [J]. Finance and Accounting News, 2018 (30): 125-128. (In Chinese)

[8] Chen Jin, Chen Yufen. Research on Performance Evaluation Index System of Enterprise Technology Innovation[J]. Science of Science and Technology Management,2006(03):86-91. (In Chinese)

[9] Wu Xiaobo, Zhu Peizhong, Wu Dong, Yao Mingming. How do the latecomers achieve rapid catch-up?-A co-modeling model of secondary business model innovation and technological innovation[J]. Science Research,2013,31(11): 1726-1735. (In Chinese)

[10] Liu Y, Wei J, Ying Y. Linking business model innovation, strategy and technology innovation: A case study [C]// International Symposium on Management of Technology. IEEE, 2012: 553-557. 